\title{
Análise da Disciplina de Contabilidade de Custos nos Cursos de Graduação em Ciências Contábeis nas Universidades Públicas do Estado da Paraíba no ano de 2019
}

\begin{abstract}
Marcia Cristina Leite Menino Bacharelado em Ciências Contábeis pela Universidade Estadual da Paraíba - UEPB Rua Nezinho Leandro, sn. Patos/PB. CEP: 58703-100 E-mail: marcinha.ccuepb@gmailc.om

Mauriceia Carvalho Nascimento Mestrado em Gestão Pública e Cooperação Internacional pela Universidade Federal da Paraíba - UFPB Prestadora de Serviços - Setor Contábil Rua Antonio Batista Gouveia, sn, Santa Rosa. Sumé/PB. CEP: 58540-000 E-mail: mauriceiasume@gmail.com

Wilton Alexandre de Melo Mestrado em Ciências Contábeis pele Universidade Federal da Paraíba - UFPB Empresário contábil e Professor Universitário da Faculdade Vale do Pajeu - FVP Rua Vicente José Bezerra, 521. Centro. Congo/PB. CEP: 58535-000 E-mail: wiltonconco@gmail.com

Ilcleidene Pereira de Freitas Mestrado em Ciências Econômicas Universidade Federal de Campina Grande - UFGC Professora Efetiva na Universidade Estadual da Paraíba - UEPB Rua Vicente Preto, 186. Alto Alegre. Sumé/PB. CEP: 58540-000 E-mail: ilcleidene@servidor.uepb.edu.br

Bruno Rodrigues Cabral Mestrado em Gestão Pública e Cooperação Internacional pela Universidade Federal da Paraíba - UFPB Rua Jarbas Moura da Costa, 52, apto. 201. Bancários. João Pessoa/PB. CEP: 58051730 E-mail: accountbruno@hotmail.com
\end{abstract}

\section{RESUMO}

O presente estudo teve como objetivo verificar os planos de ensino das disciplinas da área de custos nos cursos de graduação em ciências contábeis ofertados pelas Instituições de Ensino Superior públicas do estado da Paraíba. O ensino da contabilidade vem passando por diversas transformações. Nesse sentido as universidades buscam oferecer aos seus discentes uma base acadêmica capaz de fomentar a criação de competências e habilidades a serem utilizadas no ambiente profissional. Com relação aos procedimentos metodológicos, classificou-se como 
Análise da Disciplina de Contabilidade de Custos nos Cursos de Graduação em Ciências Contábeis nas Universidades Públicas do Estado da Paraíba no ano de 2019 Wilton Alexandre de Melo, Marcia Cristina Leite Menino, Mauriceia Carvalho Nascimento, Ilcleidene Pereira de Freitas, Bruno Rodrigues Cabral

descritiva, comparativa, de natureza qualitativa, por meio da análise documental. Os resultados evidenciaram que existe homogeneidade na estrutura dos planos de ensino diante de uma vasta pluralidade de conteúdos abordados. A metodologia de ensino mais usual é a "aula expositiva" e a forma de avaliação é a "prova objetiva/subjetiva". O livro com maior indicação nas referências é "Contabilidade de Custos", de Eliseu Martins (2010). A partir dos resultados é possível afirmar que existe uma semelhança nos planos de ensino das disciplinas da área de custos ofertadas pelas universidades públicas paraibanas. A pesquisa justifica-se por entender que o processo de formação acadêmica é fator determinante na formação de profissionais competentes e hábeis no desempenho de suas funções.

Palavras-chave: Plano de ensino. Contabilidade de Custos. Universidades Públicas.

\section{Analysis of the Cost Accouting Subject on Undergraduate Courses in Accountings Sciences at Public Universities in the State of Paraíba on 2019}

\section{ABSTRACT}

The present study aimed to verify the teaching plans of the subject in the area of costs in the undergraduate courses in accounting sciences offered by public higher education institutions in the state of Paraíba. The teaching of Accounting has has suffered several transformations. In this sense, universities seek to offer their students an academic basis capable to foment the creation of competences and skills to be used in the professional environment. Regarding methodological procedures, the present study should be classified as descriptive, comparative, in a qualitative approach, through a documentary analysis. The results showed that there is a certain homogeneity in the structure of the teaching plans in view of the vast plurality of covered contents. As the most common teaching methodology we came to find the "expository class approach" and as for the form of evaluation, the "objective / subjective test" only. The book with the highest indication on the references is "Cost Accounting", by Eliseu Martins (2010). From the results it is possible to affirm that there is a similarity in the teaching plans of the subjects in the cost area offered by the public universities in Paraíba. The research is justified by understanding that the academic training process is a determining factor on the formation of competent and skilled professionals in the performance of their duties.

Keywords: Teaching plans. Cost Accounting. Public Universities. 
Análise da Disciplina de Contabilidade de Custos nos Cursos de Graduação em Ciências Contábeis nas Universidades Públicas do Estado da Paraíba no ano de 2019 Wilton Alexandre de Melo, Marcia Cristina Leite Menino, Mauriceia Carvalho Nascimento, Ilcleidene Pereira de Freitas, Bruno Rodrigues Cabral

\section{Análisis de la Asignatura de Contabilidad de Costos en Cursos de Ggraduación em Ciencias Contables de las Universidades Públicas del Estado de Paraíba en}

2019

\section{RESUMEN}

El presente estudio tuvo por objeto verificar los planes de enseñanza de las asignaturas del área de costos en los cursos de graduación de ciencias contables ofrecidos por las instituciones públicas de enseñanza superior del Estado de Paraíba. La enseñanza de la contabilidad ha sufrido varias transformaciones. En este sentido, las universidades buscan ofrecer a sus estudiantes una base académica capaz de fomentar la creación de competencias y habilidades para ser utilizadas en el ámbito profesional. En cuanto a los procedimientos metodológicos, se clasificaron en descriptivos, comparativos, de carácter cualitativo, mediante análisis documental. Los resultados mostraron que existe homogeneidad en la estructura de los planes de enseñanza frente a una amplia pluralidad de contenidos abordados. La metodología de enseñanza más común es la "clase expositiva" y la forma de evaluación es la "prueba objetiva / subjetiva". El libro con más indicación en las referencias es "Contabilidad de costos", de Eliseu Martins (2010). De los resultados se puede afirmar que existe una similitud en los planes de enseñanza de las asignaturas del área de costos ofrecidos por las universidades públicas de Paraíba. La investigación se justifica por entender que el proceso de formación académica es un factor determinante en la formación de profesionales competentes y capacitados en el desempeño de sus funciones.

Palabras clave: Plan de enseñanza. Contabilidad de costos. Universidades Públicas.

\section{INTRODUÇÃO}

O ensino da contabilidade vem passando por diversas transformações a fim de se adequarem às exigências do mercado de trabalho (Silva, 2006). Nessa perspectiva, as universidades vêm buscando oferecer aos discentes uma base acadêmica capaz de fomentar a criação de competências e habilidades a serem utilizadas no exercício das atividades profissionais.

Ao ingressar no mercado de trabalho o profissional deverá se adequar a um novo ambiente de forma dinâmica, gerenciando, na visão de Padoan et al. (2007) "um 
Análise da Disciplina de Contabilidade de Custos nos Cursos de Graduação em Ciências Contábeis nas Universidades Públicas do Estado da Paraíba no ano de 2019

Wilton Alexandre de Melo, Marcia Cristina Leite Menino, Mauriceia Carvalho Nascimento, Ilcleidene

Pereira de Freitas, Bruno Rodrigues Cabral

turbilhão de informações e novos conhecimentos", os quais devem ser interpretados e utilizados com o objetivo de otimizar os resultados.

Sob esse enfoque, ratifica-se o papel que a contabilidade possui de gerar informações para a gestão empresarial. Tanto no campo teórico, quanto no prático, surgem novas abordagens para a contabilidade, em especial para a Contabilidade de Custos, que deixa de ser vista apenas como ferramenta auxiliar de gestão, para um emprego estratégico de controle e tomada de decisão na entidade (Cardoso, Pereira \& Guerreiro, 2007).

Para Itoz e Mineiro (2005), é necessário ter consciência que o ensino em contabilidade de custos deve acompanhar o processo de evolução do mercado econômico. O processo de ensino tem como missão de preparar o discente com conhecimentos suficientes que the permitam gerar e gerenciar informações de custos.

A contabilidade de custos deixa de ser vista apenas como uma mera técnica de avaliação de estoques para uma poderosa técnica de controle e auxílio à tomada de decisões, ganhando assim um novo enfoque, o gerencial (Martins, 2010).

Hansen e Mowen (2013) afirmam que o atual ambiente econômico gerou a necessidade de uma reestruturação da gestão de custos, dando início ao desenvolvimento de novas práticas direcionadas pela necessidade de criar e sustentar uma vantagem competitiva. No que tange a formação acadêmica, as Instituições de Ensino Superior (IES), devem dispor aos discentes, conhecimentos suficientes que the permitam gerar e gerenciar informações de custos (Ott \& Pires, 2010).

Itoz e Mineiro (2005) apontam que "o ensino da contabilidade de custos deve oferecer ao estudante referenciais que o possibilite entender o sistema de produção e seus sistemas de custeamento e elaboração de informações válidas para a tomada de decisão". Considerando o exposto, surgiu o seguinte questionamento: Quais as características das disciplinas da área de contabilidade de custos nos cursos de graduação em Ciências Contábeis nas universidades públicas da Paraíba?

O objetivo geral consiste em verificar os planos de ensino das disciplinas da área de custos nos cursos de graduação em ciências contábeis, ofertados pelas IES públicas 
Análise da Disciplina de Contabilidade de Custos nos Cursos de Graduação em Ciências Contábeis nas Universidades Públicas do Estado da Paraíba no ano de 2019

Wilton Alexandre de Melo, Marcia Cristina Leite Menino, Mauriceia Carvalho Nascimento, Ilcleidene

Pereira de Freitas, Bruno Rodrigues Cabral

da Paraíba. E os objetivos específicos: (1) Identificar as nomenclaturas utilizadas para as disciplinas de Contabilidade de Custos; (2) Verificar a estrutura dos planos de ensino das disciplinas de Contabilidade de Custos; (3) Conhecer os principais conteúdos presente nas ementas; (4) Verificar as metodologias e avaliação de ensino; (5) Pontuar as principais referências bibliográficas.

O presente estudo baseia-se na pesquisa desenvolvida por Sombra, Pessoa, Cabral, Santos e Silva (2015), que tem como tema o "Perfil da disciplina de contabilidade de custos nas universidades brasileiras: uma análise nos cursos de graduação em Ciências Contábeis". O estudo demonstrou que há certa uniformidade no perfil das disciplinas de contabilidade de custos nas universidades estudadas. Ainda, o trabalho de Guimarães, Cittadin, Giassi, Guimarães Filho e Bristot (2016) teve como objetivo, verificar se o uso de metodologias ativas no ensino de contabilidade de custos no curso de graduação em Ciências Contábeis da UNESC reflete na aprendizagem dos estudantes. Como principais resultados obtidos pelo estudo apontam que o uso da metodologia ativa contribui de forma positiva no processo de ensino-aprendizagem, contudo o uso de tal método merece cuidado, pois pode vir a sobrecarregar as atividades de professores e estudantes.

Entende-se que o processo de formação acadêmica desenvolvido nas IES se apresenta como fator determinante na formação de profissionais competentes e hábeis no desempenho de suas funções, o que só é possível se as IES estiverem em constante busca de aprimoramento das práticas de ensino-aprendizagem. Este estudo difere-se dos mencionados, pois buscou descrever especificamente o perfil das disciplinas de Contabilidade de Custos apenas nas universidades públicas paraibanas, que ofertem o curso de ciências contábeis. Nessa perspectiva, este estudo visou contribuir com a academia, pois há poucos estudos voltados à área de ensino em contabilidade de custos e espera-se também que possa contribuir para a discussão e reflexão, em especial nas IES paraibanas, no que se referem aos currículos, métodos e técnicas utilizadas nas disciplinas de custos. 
Análise da Disciplina de Contabilidade de Custos nos Cursos de Graduação em Ciências Contábeis nas Universidades Públicas do Estado da Paraíba no ano de 2019

Wilton Alexandre de Melo, Marcia Cristina Leite Menino, Mauriceia Carvalho Nascimento, Ilcleidene

Pereira de Freitas, Bruno Rodrigues Cabral

\section{REFERENCIAL TEÓRICO}

A seguir é apresentada uma revisão da literatura relacionada com o tema da pesquisa, como: as definições referentes à contabilidade de custos, ensino em contabilidade de custos e estudos anteriores.

\subsection{Contabilidade de Custos}

Ferreira (2009) traz a definição de contabilidade do $1^{\circ}$ Congresso Brasileiro de Contabilidade, datado de 1924, como sendo "a ciência que estuda e pratica as funções de orientação, de controle e de registro dos atos e fatos de uma administração econômica". Pode-se então entender a contabilidade como uma ciência social a qual estuda o patrimônio das entidades com o objetivo de fornecer informações tempestivas aos seus usuários que tomarão como base para auxiliar no processo decisório.

Até meados do século XVIII, só existia a contabilidade financeira. A partir da Revolução Industrial surgiu um novo ramo para a ciência contábil, a contabilidade de custos. A partir do processo de industrialização a apuração do custo tornou-se mais complexa, uma vez que agora o contador dispunha de uma série de valores pagos pelos fatores de produção utilizados. (Martins, 2010)

Sendo assim, verifica-se que a contabilidade está em constante transformação, buscando ser uma ciência completa para fornecer informações relevantes aos seus usuários, sejam internos ou externos. Conforme Leone (2008)

a contabilidade de custos é o ramo da Contabilidade que se destina a produzir informações para os diversos níveis gerenciais de uma entidade, como auxílio às funções de determinação de desempenho, de planejamento e controle das operações e de tomada de decisões.

Maher (2001, p. 38) conceitua a contabilidade de custos de forma breve como "o ramo da contabilidade que mede, registra e relata informações sobre custos". Tomando 
Análise da Disciplina de Contabilidade de Custos nos Cursos de Graduação em Ciências Contábeis nas Universidades Públicas do Estado da Paraíba no ano de 2019

Wilton Alexandre de Melo, Marcia Cristina Leite Menino, Mauriceia Carvalho Nascimento, Ilcleidene

Pereira de Freitas, Bruno Rodrigues Cabral

como base os autores citados pode-se entender contabilidade de custos como o ramo da contabilidade responsável por produzir informações referentes aos gastos realizados na produção de bens ou serviços, bem como gerenciá-las de forma que os gestores as utilizem como um fator de competitividade em relação aos seus concorrentes, considerando tal técnica como real e eficaz para auxiliar no processo decisório.

As terminologias utilizadas em custos, frequentemente são confundidas pela semelhança entre alguns termos, como "despesa" e "custo" que constantemente são tratadas como sinônimos, no entanto apresentam significados diferentes. A seguir apresenta-se um quadro com os principais conceitos ligados à contabilidade de custos: 
Análise da Disciplina de Contabilidade de Custos nos Cursos de Graduação em Ciências Contábeis nas Universidades Públicas do Estado da Paraíba no ano de 2019 Wilton Alexandre de Melo, Marcia Cristina Leite Menino, Mauriceia Carvalho Nascimento, Ilcleidene Pereira de Freitas, Bruno Rodrigues Cabral

\begin{tabular}{|c|c|}
\hline Termos & Descrição \\
\hline Gastos & $\begin{array}{l}\text { Compra de um produto ou serviço qualquer, que gera sacrifício financeiro para } \\
\text { a entidade, representado por entrega ou promessa de entrega de ativos }\end{array}$ \\
\hline Desembolso & Pagamento resultante da aquisição do bem ou serviço. \\
\hline Investimento & $\begin{array}{l}\text { Gasto ativado em função de sua vida útil ou de benefícios atribuíveis a futuro(s) } \\
\text { período(s). }\end{array}$ \\
\hline Despesa & $\begin{array}{l}\text { Bem ou serviço consumido direta ou indiretamente para a obtenção de } \\
\text { receitas. }\end{array}$ \\
\hline Custos & $\begin{array}{l}\text { Gasto relativo ao bem ou serviço utilizado na produção de outros bens ou } \\
\text { serviços. }\end{array}$ \\
\hline Perda & Bem ou serviço consumidos de forma anormal e involuntária. \\
\hline Custos diretos & $\begin{array}{l}\text { São os custos que podem ser apropriados diretamente aos produtos, bastando } \\
\text { haver uma medida de consumo }\end{array}$ \\
\hline Custos indiretos & $\begin{array}{l}\text { São os custos que não oferecem condição de uma medida objetiva, sendo } \\
\text { necessária para sua alocação a utilização de um critério de rateio. }\end{array}$ \\
\hline Custo fixo & $\begin{array}{l}\text { São os custos que num período têm seu montante fixado independentemente } \\
\text { de aumentos ou diminuições naquele mês do volume de produção. }\end{array}$ \\
\hline Custo variável & $\begin{array}{l}\text { São os custos que têm seu valor determinado em função da oscilação do } \\
\text { volume de producão. }\end{array}$ \\
\hline Rateio & $\begin{array}{l}\text { Representa a atribuição de um custo indireto a um objeto do custo, segundo } \\
\text { uma certa base. }\end{array}$ \\
\hline Custeio por absorção & Consiste na apropriação de todos os custos de produção aos bens elaborados. \\
\hline $\begin{array}{l}\text { Custeio baseado em } \\
\text { atividade }(A B C)\end{array}$ & $\begin{array}{l}\text { É uma metodologia de custeio que procura reduzir sensivelmente as distorções } \\
\text { provocadas pelo rateio arbitrário dos custos indiretos. }\end{array}$ \\
\hline $\begin{array}{l}\text { Custeio por processo } \\
\text { contínuo }\end{array}$ & $\begin{array}{l}\text { Consiste na elaboração dos mesmos produtos ou na prestação do mesmo } \\
\text { serviço de forma continuada por um longo período. }\end{array}$ \\
\hline Custeio por ordem & Consiste na produção de vários produtos de forma não contínua. \\
\hline $\begin{array}{ll}\text { Margem } & \text { de } \\
\text { contribuição }\end{array}$ & $\begin{array}{l}\text { É o valor que cada unidade efetivamente traz à empresa de sobra entre sua } \\
\text { receita e o custo. }\end{array}$ \\
\hline Custeio variável & $\begin{array}{l}\text { Consiste na alocação aos produtos apenas dos custos variáveis, ficando os } \\
\text { fixos separados e considerados como despesas do período, indo diretamente } \\
\text { para o Resultado. }\end{array}$ \\
\hline Ponto de equilíbrio & $\begin{array}{l}\text { Consiste no número de unidades produzidas ou vendidas onde a empresa não } \\
\text { tem lucro ou prejuízo. }\end{array}$ \\
\hline Margem de segurança & Quantidade vendida (ou valor de venda) acima do ponto de equilíbrio. \\
\hline $\begin{array}{l}\text { Alavancagem } \\
\text { operacional }\end{array}$ & $\begin{array}{l}\text { É a possibilidade de aumentar o volume de produção sem aumentar (ou } \\
\text { aumentar menos que proporcionalmente) os custos e despesas fixas. }\end{array}$ \\
\hline
\end{tabular}

\section{Quadro 1. Principais conceitos e terminologias utilizadas em custos}

Fonte: Adaptado de Martins (2010); Maher (2001); Padoveze (2010).

Hansen e Mowen (2013) afirmam que "a contabilidade de custos não é neutra; ela não fica parada nos fundos, meramente refletindo o que está acontecendo de forma imparcial. Além disso, um sistema de informações de custos também molda a 
Análise da Disciplina de Contabilidade de Custos nos Cursos de Graduação em Ciências Contábeis nas Universidades Públicas do Estado da Paraíba no ano de 2019

Wilton Alexandre de Melo, Marcia Cristina Leite Menino, Mauriceia Carvalho Nascimento, Ilcleidene

Pereira de Freitas, Bruno Rodrigues Cabral

empresa". Considerando o exposto pode-se mencionar a importância de um sistema de custos nas empresas, pois é desse o papel de fazer os cálculos que apresentem o maior lucro possível, operado em contrapartida com o menor custo, sendo esse um dos fatores responsáveis por manter as organizações operando em competitividade em meio a concorrência do mercado globalizado.

Fernandes, Soares, Fernandes, Soares e Silva (2015) afirma que a área de custos constitui uma área relevante para as organizações e bastante complexa para aqueles que estão começando nessa atividade, pois além de cálculos é necessário a interpretação de dados que subsidiarão na formação do preço de venda e, em última instância, ajudarão a determinar o desempenho da empresa. Dessa forma, a contabilidade de custos se faz necessária e importante nas organizações, pois o conhecimento de custos é vital para o desempenho das empresas.

\subsection{Ensino de Contabilidade de Custos}

Padoan et al. (2007) pontua que ensinar não é simplesmente transferir conhecimentos, mas antes de tudo é criar possibilidades para a sua produção, construção e desenvolvimento.

A partir dos vários métodos de ensino que os docentes utilizam, tem-se uma busca pelo melhor sistema de ensino-aprendizagem com o intuito de construir na graduação, primeiro nível da formação universitária, conhecimentos suficientes que permitam aos graduandos serem capazes de atender as demandas existentes no mercado, bem como para os novos desafios que possam surgir.

Libâneo (2006, p.152) entende métodos de ensino como "as ações do professor pelas quais se organizam as atividades de ensino e dos alunos para atingir objetivos de trabalho em relação a um conteúdo específico". O autor propõe alguns métodos de ensino, que serão demonstrados no Quadro 2, a seguir: 
Análise da Disciplina de Contabilidade de Custos nos Cursos de Graduação em Ciências Contábeis nas Universidades Públicas do Estado da Paraíba no ano de 2019

Wilton Alexandre de Melo, Marcia Cristina Leite Menino, Mauriceia Carvalho Nascimento, Ilcleidene

Pereira de Freitas, Bruno Rodrigues Cabral

\begin{tabular}{|l|l|}
\hline \multicolumn{1}{|c|}{ Métodos de ensino } & \multicolumn{1}{|c|}{ Características } \\
\hline Expositivo & $\begin{array}{l}\text { Os conhecimentos, habilidades e tarefas são apresentados, explicados ou } \\
\text { demonstrados pelo professor. A atividade dos alunos é receptiva, não } \\
\text { necessariamente passiva. }\end{array}$ \\
\hline Trabalho independente & $\begin{array}{l}\text { Consiste de tarefas dirigidas e orientadas pelo professor, para que alunos as } \\
\text { resolvam de modo relativamente independente criador. }\end{array}$ \\
\hline Elaboração conjunta & $\begin{array}{l}\text { É uma forma de iteração ativa entre o professor e os alunos visando a } \\
\text { obtenção de novos conhecimentos, habilidades, atitudes e convicções, bem } \\
\text { como a fixação e consolidação de conhecimento de conviç̧ões já adquiridas. }\end{array}$ \\
\hline Trabalho em grupo & $\begin{array}{l}\text { Consiste basicamente em distribuir temas de estudo iguais ou diferentes a } \\
\text { grupos fixos ou variáveis, usando o critério de alunos de diferentes } \\
\text { rendimentos escolares. }\end{array}$ \\
\hline Atividades especiais & $\begin{array}{l}\text { São aqueles que complementam os métodos de ensino e que concorre com a } \\
\text { assimilação de conteúdo, como visitas a museus, jornal escolar etc. }\end{array}$ \\
\hline
\end{tabular}

Quadro 2. Métodos de ensino

Fonte: Adaptado de Libâneo (2006).

Nas disciplinas específicas da área de custos, é necessário que o professor utilize de métodos e técnicas para apresentar os conteúdos de maneira mais prática e clara possível, tendo em vista a complexidade dos assuntos abordados nessa disciplina. Duarte, Cruz, Santos, Neto, Lagioia e Santos (2016) apontou como principais causas de reprovação na disciplina de custos na perspectiva dos discentes, em um estudo realizado em uma IES paraibana, como sendo as metodologias pouco estimulantes, desempenho do docente e a dificuldade de assimilação do conteúdo.

Ferreira (2009) afirma que os professores de contabilidade precisarão,

desenvolver técnicas de ensino que permitam a permanência da visão histórica, com o intuito de mostrar o estoque de conhecimentos que a área contábil pode desenvolver, e ao mesmo tempo abrir horizontes dos futuros contadores para a atualidade e o futuro.

O professor de custos deve buscar a melhor didática possível, com o objetivo de transmitir o conteúdo de forma ampla e satisfatória, a fim de alcançar os melhores resultados possíveis no que concerne ao ensino-aprendizagem dos discentes, bem como o processo de avaliação. O processo de avaliar não deve ser visto apenas como 
Análise da Disciplina de Contabilidade de Custos nos Cursos de Graduação em Ciências Contábeis nas Universidades Públicas do Estado da Paraíba no ano de 2019

Wilton Alexandre de Melo, Marcia Cristina Leite Menino, Mauriceia Carvalho Nascimento, Ilcleidene Pereira de Freitas, Bruno Rodrigues Cabral

mera atribuição de notas. Deve antes de tudo, auxiliar os docentes na construção de resultados que tenha como principal objetivo a aprendizagem e o desenvolvimento dos discentes, de forma a auxiliar o seu crescimento (Luckesi, 2006).

$\mathrm{Na}$ busca de afinar a relação ensino superior e demandas de mercado, o currículo das disciplinas dos cursos de graduação são desenvolvidos com a exigibilidade de requisitos mínimos das Diretrizes Curriculares Nacionais (DCNs). O Curso de Graduação em Ciências Contábeis possui estrutura curricular fundamentada em DCNs específicas de acordo com a Resolução CNE/CES №10/2004, definindo a base a ser ensinada (Silva \& Souza, 2012).

Ao refletir sobre as DCNs para o Curso de Graduação em Ciências Contábeis, o art. $5^{\circ}$ da Resolução CNE/CES 10, de 16 de dezembro de 2004, dispõe sobre o perfil de formação do futuro profissional em três categorias, sendo: conteúdos de formação básica, formação profissional e formação teórico-prática, detalhado no Quadro 3.

\begin{tabular}{|c|l|}
\hline Conteúdos & \multicolumn{1}{|c|}{ Descrição } \\
\hline Formação Básica & $\begin{array}{l}\text { Compreende os estudos relacionados com outras áreas do conhecimento, } \\
\text { sobretudo Administração, Economia, Direito, Métodos Quantitativos, } \\
\text { Matemática e Estatística. }\end{array}$ \\
\hline Formação Profissional & $\begin{array}{l}\text { Aborda os estudos específicos atinentes às Teorias da Contabilidade, } \\
\text { incluindo as noções das atividades atuariais e de quantificações de } \\
\text { informações financeiras, patrimoniais, governamentais e não- } \\
\text { governamentais, de auditorias, perícias, arbitragens e controladoria, com } \\
\text { suas aplicações peculiares ao setor público e privado. }\end{array}$ \\
\hline $\begin{array}{c}\text { Formação Teórico- } \\
\text { Prática }\end{array}$ & $\begin{array}{l}\text { Estágio Curricular Supervisionado, Atividades Complementares, Estudos } \\
\text { Independentes, Conteúdos Optativos, Prática em Laboratório de Informática } \\
\text { utilizando softwares atualizados para Contabilidade. }\end{array}$ \\
\hline
\end{tabular}

\section{Quadro 3. Conteúdos obrigatórios na formação em ciências contábeis}

Fonte: Adaptado da Resolução CNE/CES n 10/2004.

Nesse contexto, verifica-se que a formação do profissional contábil deve abordar, em salas de aula, conceitos que contemplem situações vividas no dia a dia das empresas, permitindo assim que a graduação se apresente eficiente e congruente com o mercado. Entre as disciplinas presentes, na graduação contábil, a contabilidade de 
Análise da Disciplina de Contabilidade de Custos nos Cursos de Graduação em Ciências Contábeis nas Universidades Públicas do Estado da Paraíba no ano de 2019

Wilton Alexandre de Melo, Marcia Cristina Leite Menino, Mauriceia Carvalho Nascimento, Ilcleidene

Pereira de Freitas, Bruno Rodrigues Cabral

custos é obrigatória na estrutura curricular dos cursos ofertados pelas IES, uma vez que essa é uma área específica de atuação do contador (Itoz \& Mineiro, 2005).

Padoan et al. (2007) consideram que "a Contabilidade de Custos passou a ter uma importância crucial na formação do contador". O profissional contábil da área de custos é responsável por toda mensuração dos atos e fatos patrimoniais de uma entidade que decorrem dos recursos utilizados na produção de bens ou serviços.

Nossa (1999) destaca que,

É importante que se tenha uma ligação da teoria com a prática naquilo que é apresentado ao aluno, para que este se sinta seguro em relação ao conteúdo de sua aprendizagem, o qual é imprescindível para sua formação profissional. Para que isso aconteça, no entanto, é necessário que o professor seja conhecedor dessa dialética: teoria e prática.

Diante do exposto, é possível afirmar que uma boa formação acadêmica demanda três elementos essenciais e consonantes: a IES responsável pela formação superior dos discentes; os docentes responsáveis pelo ensino associando teoria e prática e com isso desenvolvendo competências e habilidades no educando; e os discentes que devem empenhar-se em participar do processo ensino-aprendizagem de forma ampla e satisfatória.

\subsection{Estudos Anteriores}

Por meio da revisão da literatura, pode-se perceber que existem poucas pesquisas voltadas para a área de ensino, especificamente na área de custos, objeto do presente estudo. A seguir serão apresentados alguns estudos relacionados e suas principais contribuições.

Silva (1995) buscou alertar acerca das deficiências existentes no ensino das disciplinas de Contabilidade de Custos nos cursos de graduação, principalmente no que se refere ao distanciamento entre o ensino e a prática organizacional. $O$ autor concluiu que o ensino em Contabilidade de Custos deve acompanhar as mudanças do mundo 
Análise da Disciplina de Contabilidade de Custos nos Cursos de Graduação em Ciências Contábeis nas Universidades Públicas do Estado da Paraíba no ano de 2019

Wilton Alexandre de Melo, Marcia Cristina Leite Menino, Mauriceia Carvalho Nascimento, Ilcleidene

Pereira de Freitas, Bruno Rodrigues Cabral

organizacional com a finalidade de responder às necessidades de seus usuários, caso contrário o ensino nessa área se tornará obsoleto e dispensável.

O estudo realizado por Itoz e Mineiro (2005) relata como principais conteúdos contemplados nas ementas das disciplinas relacionadas a custos, tais como: introdução a contabilidade de custos; princípios e terminologia contábeis aplicados aos custos; tratamento de receita e despesas na contabilidade de custos; custeamento e controle de material direto; mão de obra direta e indireta e dos custos gerais de produção; produção por ordem e produção continua; sistemas de acumulação de custos; coprodutos e subprodutos; relação custo-volume-lucro; custo padrão e analise de variâncias.

Padoan et al. (2007) realizaram um estudo com o objetivo de identificar os principais métodos e técnicas utilizados pelos docentes que lecionam as disciplinas de custos nas universidades públicas do Paraná. Os resultados do estudo apontaram como métodos mais utilizados a "aula expositiva" e a "resolução de exercícios", contudo os docentes apontaram como mais eficiente a "resolução de exercícios" e a "dinâmica em grupo", e como pouco eficiente o "uso do laboratório de informática". Os autores concluíram que há uma predisposição por parte dos docentes em utilizar o que por eles é considerado como eficiente.

O estudo de Ferreira et al. (2011) analisou os planos de ensino das disciplinas de Contabilidade de Custos, nos cursos de graduação em Administração e Negócios das universidades norte-americanas, através de uma pesquisa documental em 16 planos de ensino, qualificadas pelo ranking da Revista Business Week. Os resultados demonstraram que há certa homogeneidade na estrutura dos planos analisados, as "aulas expositivas e "atividades de casa" foram apontadas como as metodologias mais utilizadas, as técnicas de avaliação mais comuns são as "provas" e "participação/presença", quanto à bibliografia apenas um livro é utilizado dentre os 15 dos planos analisados, por fim os autores constataram que existe uma certa padronização no perfil das disciplinas pesquisadas. 
Análise da Disciplina de Contabilidade de Custos nos Cursos de Graduação em Ciências Contábeis nas Universidades Públicas do Estado da Paraíba no ano de 2019 Wilton Alexandre de Melo, Marcia Cristina Leite Menino, Mauriceia Carvalho Nascimento, Ilcleidene Pereira de Freitas, Bruno Rodrigues Cabral

Sombra et al. (2015) realizaram um estudo do tipo documental com o objetivo de identificar o perfil das disciplinas de Contabilidade de Custos nos cursos de graduação em Ciências Contábeis nas universidades brasileiras. Foram analisados 24 planos de ensino, referente à 18 universidades entre as 50 primeiras classificadas pelo Ranking Universitário Folha 2014. Os resultados do estudo demonstraram que há certa padronização no perfil das disciplinas de Contabilidade de Custos nas universidades estudadas, pois os planos apresentaram basicamente os mesmos elementos, a "aula expositiva" apresenta-se como método mais utilizado, no que tange a avaliação a "prova" é a forma mais usual, e como bibliografia mais indicada encontra-se o livro "Contabilidade de Custo" de Eliseu Martins.

\section{PROCEDIMENTOS METOdOLÓGICOS}

Pesquisar é investigar um fato, novo ou não, em busca de esclarecê-los acerca de algum problema. Para Gil (2012), pesquisa é o procedimento racional e sistemático que tem como objetivo proporcionar respostas aos problemas que são propostos. A pesquisa pode ser classificada conforme, Gerhardt e Silveira (2009) em quatro tipos: quanto à sua abordagem, sua natureza, seus objetivos e seus procedimentos. Quanto à natureza e abordagem a pesquisa classifica-se como qualitativa. $O$ método qualitativo não emprega instrumentos estatísticos como base no processo de análise de um problema, não há intenção de numerar ou medir unidades ou categorias homogêneas (Richardson, 2008).

Quanto aos objetivos é do tipo descritivo e comparativo, pois busca descrever e comparar o perfil das disciplinas nas áreas de Contabilidade de Custos ofertadas pelas universidades públicas da Paraíba. Para Gil (2012), as pesquisas desse tipo têm como objetivo descrever as características de determinada população ou fenômeno. E comparativo, como a investigação de indivíduos, classes, fenômenos ou fatos, com o intuito de apresentar as divergências e semelhanças entre eles. 
Análise da Disciplina de Contabilidade de Custos nos Cursos de Graduação em Ciências Contábeis nas Universidades Públicas do Estado da Paraíba no ano de 2019 Wilton Alexandre de Melo, Marcia Cristina Leite Menino, Mauriceia Carvalho Nascimento, Ilcleidene Pereira de Freitas, Bruno Rodrigues Cabral

Essa pesquisa assim caracteriza-se por buscar descrever e comparar os planos de ensino das disciplinas da área de custos nos cursos de graduação em ciências contábeis ofertados pelas IES públicas da Paraíba no ano de 2019 de forma qualitativa, ou seja, será realizada uma conferência dos documentos. No que se refere aos procedimentos, a mesma se caracteriza como documental, uma vez que foram analisados os planos de ensino das disciplinas relacionadas à área de custos das IES públicas da Paraíba. Nesse sentido, Gil (2012) considera que a pesquisa documental tem como objetivo analisar fontes que ainda não foram trabalhadas ou que ainda poderão ser analisados de acordo com os objetivos da pesquisa.

Este estudo contempla todas as três universidades públicas paraibanas, sendo duas universidades federais e uma estadual, sendo elas: Universidade Federal da Paraíba (UFPB), Universidade Federal de Campina Grande (UFCG) e Universidade Estadual da Paraíba (UEPB). Escolhida a população, realizou-se uma busca nos sites das instituições. Todas elas ofertam o curso de graduação em Ciências Contábeis, sendo: um curso ofertado pela UFCG, em relação a UFPB e UEPB, ambas ofertam o curso em dois campis diferentes.

Foi realizada uma busca nos sites dos respectivos cursos, em busca dos Projetos Pedagógicos dos Cursos (PPCs), Matrizes Curriculares e Planos de Ensino. Para os dados que não se encontravam nas páginas dos cursos, foi realizado contato via email, obtendo-se retorno de quatro cursos, ficando um dos cursos da UFPB de fora por não envio. Em função do tempo da execução da pesquisa, optou-se por descartar. Observou-se que os dois cursos ofertados pela UEPB apresentam matrizes curriculares distintas. Sendo assim, os cursos foram analisados separadamente, e não por instituição. Ainda, um dos cursos da UEPB dispõe de três disciplinas na área de custos e o outro apresenta apenas duas, o curso da UFPB oferta em sua grade curricular duas disciplinas na área de Contabilidade de custos, o mesmo acontece com o curso da UFCG. Sendo assim, o presente trabalho analisou nove planos de ensino das disciplinas de custos, referente a quatro cursos de graduação em ciências contábeis ofertados pelas três IES públicas da Paraíba. 
Análise da Disciplina de Contabilidade de Custos nos Cursos de Graduação em Ciências Contábeis nas Universidades Públicas do Estado da Paraíba no ano de 2019

Wilton Alexandre de Melo, Marcia Cristina Leite Menino, Mauriceia Carvalho Nascimento, Ilcleidene

Pereira de Freitas, Bruno Rodrigues Cabral

A partir dessa análise foi conferido o número de vezes que os itens referentes a metodologias, avaliação, conteúdo, dentre outros itens presentes nos planos foram mencionados, tomando como parâmetro o esquema básico apresentado por Tosi (2006), os quais devem abordar no mínimo: dados identificativos, objetivos, avaliação, bibliografia, conteúdo e metodologia. Assim, realizou-se a conferência das informações comuns e diferentes sobre os itens apresentados nos planos de ensino.

\section{ANÁLISE E DISCUSSÃO DOS RESULTADOS}

A seguir busca-se apresentar os resultados obtidos a partir das análises realizadas nos nove planos de cursos, referentes as três IES públicas paraibanas que ofertam o curso de Ciências Contábeis.

\subsection{Nomenclatura das Disciplinas que Abordam Contabilidade de Custos}

Por meio dos planos de ensino analisados, primeiramente buscou-se saber quais os nomes das disciplinas que abordam a temática de custos nos cursos de graduação em Ciências Contábeis nas universidades públicas do estado paraibano. A Tabela 01 apresenta os resultados obtidos, a qual está apresentada em ordem decrescente do número de menções.

Tabela 01

Nome das disciplinas que abordam custos

\begin{tabular}{lcc}
\hline Nome das disciplinas & Menções & $\%$ \\
\hline Análise de custos & 4 & 44,44 \\
Contabilidade de Custos & 3 & 33,33 \\
Contabilidade de Custos I & 1 & 11,11 \\
Contabilidade de Custos II & 1 & 11,11 \\
\hline
\end{tabular}

Nota. Fonte: Dados da pesquisa (2019). 
Análise da Disciplina de Contabilidade de Custos nos Cursos de Graduação em Ciências Contábeis nas Universidades Públicas do Estado da Paraíba no ano de 2019 Wilton Alexandre de Melo, Marcia Cristina Leite Menino, Mauriceia Carvalho Nascimento, Ilcleidene

Pereira de Freitas, Bruno Rodrigues Cabral

Percebe-se que a nomenclatura mais utilizada entre as IES públicas paraibanas é Análise de custos que representa $44,4 \%$ em relação aos nove planos analisados, contudo observou-se que dos quatro cursos analisados, cada um oferece no mínimo duas disciplinas referentes a essa temática, sendo assim, considerando o número de cursos, a disciplina de Análise de custos se faz presente em $100 \%$ dos cursos, já a disciplina de Custos I e II apresenta-se apenas em um dos cursos ofertado pela UEPB, e a disciplina Contabilidade de custos está presente nos cursos da UFPB, UEPB e UFCG, sendo assim pode-se evidenciar que as nomenclaturas utilizadas pelas IES apresentam-se em uniformidade nas universidades paraibanas.

\subsection{Estrutura dos Planos de Ensino}

Para Tosi (2006) o plano de ensino é o projeto que dá vida ao desempenho do docente, o qual consiste em uma previsão de organização do ensino. Dessa forma, o plano de ensino pode ser considerado como um condutor do trabalho a ser desenvolvido em sala de aula, por parte dos docentes. A autora ainda recomenda que a estrutura mínima a ser apresentada em um programa de ensino, a saber, dados identificativos, justificativa, diagnose, objetivos, conteúdo, metodologia, avaliação e bibliografia. Tomando como parâmetro, analisou-se a estrutura apresentada nos programas de ensino dos cursos estudados (Tabela 02). 
Análise da Disciplina de Contabilidade de Custos nos Cursos de Graduação em Ciências Contábeis nas Universidades Públicas do Estado da Paraíba no ano de 2019 Wilton Alexandre de Melo, Marcia Cristina Leite Menino, Mauriceia Carvalho Nascimento, Ilcleidene Pereira de Freitas, Bruno Rodrigues Cabral

Tabela 02

Estrutura dos planos de ensino

\begin{tabular}{lcc}
\hline Estrutura dos planos de ensino & Menções & $\%$ \\
\hline Dados identificativos & 9 & 100 \\
Ementa & 9 & 100 \\
Objetivos & 9 & 100 \\
Conteúdo & 9 & 100 \\
Metodologia & 9 & 100 \\
Procedimentos de Avaliação de Aprendizagem & 9 & 100 \\
Referências Bibliográficas & 9 & 100 \\
Habilidades e competências & 2 & 22,22 \\
Horário de atendimento & 1 & 11,11 \\
Cronograma & 1 & 11,11 \\
\hline
\end{tabular}

Nota. Fonte: Dados da pesquisa (2019).

A Tabela 02 evidencia que há certa homogeneidade na estrutura utilizada nos planos de ensino das IES públicas paraibanas, dos dez itens que foram identificados, sete deles aparecem em todos os planos, apenas "habilidades e competências", foram encontrados em apenas dois planos, sendo na disciplina de contabilidade de custos ofertado pela UFCG e UFPB. O "horário de atendimento" e "cronograma" está presente apenas no plano da disciplina de contabilidade de custos, ofertado pela UFPB. Tomando como base a estrutura apresentada por Tosi (2006), a qual descreve oito passos para a composição de um programa de ensino, as IES paraibanas, observam seis desses passos, ficando de fora apenas a "justificativa" e "diagnose", dessa forma, é possível identificar uma considerável utilização dos principais componentes do modelo apresentado pela autora.

Confrontando os resultados obtidos neste estudo, quanto à composição dos planos de ensino, e os resultados obtidos por Sombra et al. (2015), constatou-se similaridade nos resultados, pois elementos como "ementa", "objetivo, "conteúdo" tiveram uma grande representatividade, já o elemento "cronograma" apareceu com certa discrepância em ambos os estudos. 
Análise da Disciplina de Contabilidade de Custos nos Cursos de Graduação em Ciências Contábeis nas Universidades Públicas do Estado da Paraíba no ano de 2019

Wilton Alexandre de Melo, Marcia Cristina Leite Menino, Mauriceia Carvalho Nascimento, Ilcleidene Pereira de Freitas, Bruno Rodrigues Cabral

\subsection{Principais Conteúdos Abordados}

Esta seção visa apresentar os principais conteúdos programáticos apresentado nos planos de ensino analisados, vale lembrar que pelo fato de cada curso ofertar mais de uma disciplina na área de custos, apenas um tópico fora mencionado em todos os planos. A Tabela 03 apresenta os principais tópicos citados nos planos de ensino.

Tabela 03

\section{Principais conteúdos abordados}

\begin{tabular}{lcc}
\hline Conteúdos Programáticos & Menções & $\%$ \\
\hline Sistemas de custeio & 9 & 100 \\
Formação de preço de venda & 5 & 55,56 \\
Terminologia e classificação dos custos & 4 & 44,44 \\
Custeio Baseado em Atividade (ABC) & 4 & 44,44 \\
Análise Custo-volume-lucro (CVL) & 4 & 44,44 \\
Contextualização da contabilidade de custos & 3 & 33,33 \\
Elementos de custo & 3 & 33,33 \\
Custos para planejamento e controle & 3 & 33,33 \\
Análise das variações de custo & 3 & 33,33 \\
Contabilização dos custos & 3 & 33,33 \\
Princípios básicos de custos & 2 & 22,22 \\
Mecanismos de apuração de custos & 2 & 22,22 \\
Método de separação dos custos & 2 & 22,22 \\
Orçamento flexível e avaliação de desempenho & 2 & 22,22 \\
Gestão estratégica de custos & 1 & 11,11 \\
Aplicação de métodos quantitativos & 1 & 11,11 \\
\hline
\end{tabular}

Nota. Fonte: Dados da pesquisa (2019).

Considerando os dados apresentados na Tabela 03, pode-se perceber que 0 conteúdo mais abordado nas disciplinas de custos das IES públicas paraibana, é o "sistema de custeio", uma vez que fora considerado neste tópico "custeio por absorção", "custeio variável", "sistema de custo por processo contínuo" e por "ordem", sendo alguns desses abordados na primeira disciplina de custos, por serem introdutórios, e outros visto em uma segunda disciplina, voltada a parte gerencial e estratégica.

De forma geral, observa-se que as disciplinas de custos contém uma grande pluralidade de conteúdo, e por serem esses de grande complexidade são trabalhados em sala de aula de forma detalhada. Apenas dois tópicos apresentaram-se 
Análise da Disciplina de Contabilidade de Custos nos Cursos de Graduação em Ciências Contábeis nas Universidades Públicas do Estado da Paraíba no ano de 2019

Wilton Alexandre de Melo, Marcia Cristina Leite Menino, Mauriceia Carvalho Nascimento, Ilcleidene

Pereira de Freitas, Bruno Rodrigues Cabral

discrepantes, sendo "gestão estratégica de custos" e "aplicação de métodos quantitativos na gestão de custos" o primeiro está presente apenas na disciplina de análise de custos ofertada pela UFCG, e o segundo presente também na disciplina de análise de custos, de um dos cursos ofertados pela UEPB.

Confrontando os resultados obtidos, com os achados de Sombra et al. (2015) verificou-se que os conteúdos identificados neste trabalho foram semelhantes no que se referem a parte introdutória da disciplina de custos, como "terminologias aplicadas a custo", "métodos de custeio" e "apuração dos custos", no entanto apresentou divergência no sentido de que foram observados neste estudo tópicos voltados a gestão de custos, o que não fora identificado naquele estudo.

\subsection{Metodologias de Ensino}

Tosi (2006) conceitua metodologia como sendo um conjunto de métodos, técnicas e procedimentos, determinados em um cronograma, tendo em vista atingir, com sucesso, objetivos previamente determinados. A Tabela 04 demonstra os principais métodos e técnicas utilizados pelos docentes nas IES públicas paraibanas.

Tabela 04

\section{Metodologias de ensino utilizadas}

\begin{tabular}{lcc}
\hline Metodologia & Menções & $\%$ \\
\hline Aula expositiva & 9 & 100 \\
Resolução de exercícios em grupo e individuais & 6 & 66,67 \\
Estudos de caso & 5 & 55,56 \\
Discussões grupo & 3 & 33,33 \\
Pesquisas bibliográficas & 1 & 11,11 \\
Seminários & 1 & 11,11 \\
Trabalhos escritos & 1 & 11,11 \\
\hline
\end{tabular}

Nota. Fonte: Dados da pesquisa (2019).

Como se pode observar, a metodologia mais usual é a "aula expositiva", estando presentes em $100 \%$ dos planos. Os procedimentos apontados como menos utilizados foram "pesquisa bibliográfica", "seminários" e "trabalhos escritos", estando o primeiro 
Análise da Disciplina de Contabilidade de Custos nos Cursos de Graduação em Ciências Contábeis nas Universidades Públicas do Estado da Paraíba no ano de 2019

Wilton Alexandre de Melo, Marcia Cristina Leite Menino, Mauriceia Carvalho Nascimento, Ilcleidene

Pereira de Freitas, Bruno Rodrigues Cabral

presente na disciplina de Contabilidade de Custos I, já o segundo e o terceiro estão presentes na disciplina de Contabilidade de Custo II, ambas são ofertadas em um dos cursos da UEPB.

Os resultados encontrados apresentaram-se semelhantes, aos achados por Padoanet al. (2007) e Sombra et al. (2015), em ambos os estudos a "aula expositiva" foi citada como a metodologia mais utilizado por parte dos docentes. As metodologias "pesquisas bibliográficas", "seminários" e "trabalhos escritos", foram as menos utilizadas por todos os cursos, possivelmente pelo fato de a disciplina possuir um caráter mais prático, exigindo a resolução de questões.

\subsection{Procedimentos de Avaliação de Aprendizagem}

Libâneo (2006, p.195) conceitua avaliação como "uma tarefa didática, necessária e permanente do trabalho do docente, o qual deve acompanhar passo a passo 0 processo de ensino-aprendizagem". Desse modo, entende-se que os procedimentos de avaliação devem ser realizados de forma contínua, sendo necessário que os docentes busquem os melhores métodos, de forma que os objetivos traçados para a disciplina sejam alcançados. A Tabela 05 demonstra quais os procedimentos empregados na avaliação de aprendizagem.

Tabela 05

Procedimentos de avaliação

\begin{tabular}{lcc}
\hline Avaliação & Menções & $\%$ \\
\hline Prova objetiva/subjetiva & 7 & 77,78 \\
Trabalhos em grupo e individual/Apresentação & 4 & 44,44 \\
Avaliações periódicas/contínua & 2 & 22,22 \\
Estudos de caso & 2 & 22,22 \\
Relatório prático & 1 & 11,11 \\
Resolução de exercícios & 1 & 11,11 \\
\hline
\end{tabular}

Nota. Fonte: Dados da pesquisa (2019).

A forma de avaliação mais utilizada entre os docentes é a "prova objetiva/subjetiva" sendo apontada em sete dos nove planos analisados, o que 
Análise da Disciplina de Contabilidade de Custos nos Cursos de Graduação em Ciências Contábeis nas Universidades Públicas do Estado da Paraíba no ano de 2019

Wilton Alexandre de Melo, Marcia Cristina Leite Menino, Mauriceia Carvalho Nascimento, Ilcleidene

Pereira de Freitas, Bruno Rodrigues Cabral

corresponde a $77,8 \%$ da amostra analisada, seguido de "trabalhos em grupo e individual/apresentação" que foram mencionados em quatro planos o que representa $44,4 \%$ dos nove analisados. A análise ficou prejudicada no item "avaliação periódica", pois fora mencionada deforma genérica. A avaliação por "relatório prático" foi mencionada apenas em um dos cursos ofertados pela UEPB, no plano o docente especificou a forma de ser feito o relatório, sendo solicitado aos discentes uma análise do processo de cálculo dos custos e formação de preço de venda de um produto, sendo essa uma forma de avaliar que buscar unir o binômio teoria-prática.

A pesquisa realizada por Sombra et al. (2015) e Ferreira et al. (2011), demonstrou que a "aplicação de provas" também foram os métodos de avaliação mais utilizadas, nas disciplinas de contabilidade de custos nos cursos de graduação em Ciências Contábeis nas universidades brasileiras e nos cursos de graduação em Administração e Negócios nas universidades norte-americanas, respectivamente.

\subsection{Referências Bibliográficas Utilizadas}

Analisando as referências bibliográficas, observou-se a pluralidade de autores indicados nos planos estudados, no total foram mencionadas 30 (trinta) obras, sinalizadas no plano de ensino como básica e complementar. Optou-se pela não separação das referências, porque em alguns planos uma determinada referência era considerada básica, já em outros era considerada como complementar. Sendo assim, decidiu-se por apresentar o resultado de forma geral, demonstrando a seguir na Tabela 06. 

Análise da Disciplina de Contabilidade de Custos nos Cursos de Graduação em Ciências
Contábeis nas Universidades Públicas do Estado da Paraíba no ano de 2019 Wilton Alexandre de Melo, Marcia Cristina Leite Menino, Mauriceia Carvalho Nascimento, Ilcleidene Pereira de Freitas, Bruno Rodrigues Cabral

Tabela 06

Referências utilizadas

Referências Bibliográficas

MARTINS, Eliseu. Contabilidade de custos. 9. ed. São Paulo: Atlas, 2010.

MAHER, Michael. Contabilidade de custos: criando valor para administração. São Paulo:

Atlas, 2001.

HORNGREN, Charles T; FORTER, Eric W. Contabilidade de custos: um enfoque

administrativo. São Paulo: Prentice Hall, 2004.

GARRISON, Ray H; NOREEN, Eric W; BREWER, Peter C. Contabilidade gerencial. São

Paulo:McGraw Hill, 2013.

NAKAGAWA, Masayuki. ABC: custeio baseado em atividades. 2. ed. São Paulo: Atlas, 2001.

HORNGREN, C. T. Contabilidade de custos. São Paulo: Atlas, 2002

LEONE, G S. G. Custos: planejamento implantação e controle. São Paulo: Atlas, 2000

ATKINSON, Anthony A.; BANKER, Rajiv D.; KAPLAN, Robert S. Contabilidade gerencial.

2. ed. São Paulo: Atlas, 2008

NASCIMENTO, Josenilton Mendes do. Custos: planejamento, controle e gestão na economia globalizada. 2 ed. São Paulo: Atlas, 2011.

IUDÍCIBUS, Sergio de. Análise de custos. São Paulo: Atlas, 2010.

LEONE, George S. Guerra. LEONE, Rodrigo José Guerra.Curso de contabilidade de

custos. São Paulo: Atlas, 2000.

BORNIA, Antonio Cezar. Análise gerencial de custos: aplicação em empresas modernas.

São Paulo: Atlas, 2009.

CREPALDI, Silvio Aparecido. Curso básico de contabilidade de custos. 4. ed. São Paulo:

Atlas, 2009.

SANTOS, Joel José dos. Análise de custos: um enfoque gerencial. São Paulo: Atlas, 2010.

NAKAGAWA, Masayuki. Gestão estratégica de custos. São Paulo: Atlas, 1991.

FERREIRA, José Antônio Stark. Contabilidade de custo. São Paulo : Prentice Hall, 2007.

NEVES, Silvério das; VICECONTI, Paulo E. V. Contabilidade de custos: um enfoque direto e objetivo. 6 ed. São Paulo: Frase, 2000.

RIBEIRO, Osni Moura. Contabilidade de custos. 9.ed. São Paulo: Saraiva, 2014.

HANSEN, Don R.; MOWEN, Maryanne M. Gestão de custos: contabilidade e controle. 1.

ed. São Paulo: Pioneira Thomson Learnig, 2001.

MARTINS, Eliseu; ROCHA, Welington. Contabilidade de custos: livro de exercícios. 10. ed.

são paulo: atlas, 2010.

MARTINS, Eliseu; ROCHA, Welington. Métodos de custeio comparados: custos e margens analisados sob diferentes perspectivas. São Paulo: Atlas, 2010.

BERTÓ, Dalvio José; BEULKE, Rolando. Gestão de custos. São Paulo: Saraiva, 2006.

GUERREIRO, Reinaldo. Estruturação de sistemas de custos para a gestão da

rentabilidade. 1. ed. São Paulo: Atlas, 2010.

ALLORA, V: GANTZEL, N. Revolução nos custos. Salvador. Casa da Qualidade, 1996.

COGAN, S. Custos e preços: formação e análise. São Paulo: Pioneira Thomson Learning, 2002.

ELDENBURG, L. G;WOLCOTT, S. K. Gestão de custos: como medir, monitorar e motivar o desempenho. Rio de Janeiro: LTC, 2007

SANTOS, Joel J. Contabilidade e análise de custos: modelo contábil. Métodos de

depreciação. ABC - custeio baseado em atividades. Análise atualizada de encargos

sociais sobre salários. 5. ed. São Paulo: Atlas, 2009.

JOHNSON, H. Thomas, KAPLAN, Robert S. A relevância da contabilidade de custos. São

Paulo. Atlas, 2001

\begin{tabular}{|c|c|}
\hline Menções & $\%$ \\
\hline 9 & 100,00 \\
\hline 5 & 55,56 \\
\hline 5 & 55,56 \\
\hline 4 & 44,44 \\
\hline 3 & 33,33 \\
\hline 3 & 33,33 \\
\hline 3 & 33,33 \\
\hline 3 & 33,33 \\
\hline 3 & 33,33 \\
\hline 3 & 33,33 \\
\hline 3 & 33,33 \\
\hline 2 & 22,22 \\
\hline 2 & 22,22 \\
\hline 2 & 22,22 \\
\hline 2 & 22,22 \\
\hline 2 & 22,22 \\
\hline 2 & 22,22 \\
\hline 2 & 22,22 \\
\hline 2 & 22,22 \\
\hline 2 & 22,22 \\
\hline 2 & 22,22 \\
\hline 2 & 22,22 \\
\hline 2 & 22,22 \\
\hline 1 & 11,11 \\
\hline 1 & 11,11 \\
\hline 1 & 11,11 \\
\hline 1 & 11,11 \\
\hline 1 & 11,11 \\
\hline
\end{tabular}

193

ABCustos, São Leopoldo: Associação Brasileira de Custos, v. 15, n. 3, p. 171-199, set./dez. 2020 
Análise da Disciplina de Contabilidade de Custos nos Cursos de Graduação em Ciências Contábeis nas Universidades Públicas do Estado da Paraíba no ano de 2019 Wilton Alexandre de Melo, Marcia Cristina Leite Menino, Mauriceia Carvalho Nascimento, Ilcleidene Pereira de Freitas, Bruno Rodrigues Cabral

PEREZ JR. José Hernandez. Gestão estratégica de custos. São Paulo: Atlas, 2003.

Nota. Fonte: Dados da pesquisa (2009).

Tomando por base os resultados apresentados, percebe-se que a obra de Martins (2010), "Contabilidade de Custos", foi a mais mencionada, alcançando 100\% dos planos analisado. Em seguida, Maher (2001) Horngren, Datar e Foster (2004) foram mencionados em cinco planos, o primeiro fora citado em dois planos de um dos cursos da UEPB, dois da UFCG e um da UFPB, o segundo foi citado em quatro planos da UEPB e um da UFPB que representa 55,6\% em relação à amostra total. Garrison, Noreen e Brewer (2011) foram mencionados em quatro planos, sendo os quatro citados nos dois cursos ofertados pela UEPB.

Nakagawa (2001), Atkinson, Banker e Kaplan (2008), Nascimento (2011), ludícibus (2010), Leone e Leone (2000) e Horngren (2002) foram mencionados em três planos cada, sendo dois planos dos cursos da UEPB e um da UFCG. Leone (2000) como único autor foi mencionado três vezes, em dois planos da UFCG e um da UEPB.

Os autores Bornia (2009), Crepaldi (2009) e Santos (2010), foram mencionados duas vezes, no plano de uma das disciplinas da UFPB e UFCG. Nakagawa (1991), Ferreira (2007), Neves e Viceconti (2000), Ribeiro (2014), Hansen e Mowen (2001), Martins e Rocha (2010), Martins e Rocha (2010), Bertó e Beulke (2006) e Guerreiro (2010) foram mencionados também duas vezes, nos planos da UEPB.

Allora e Gantzel (1996), Cogan (2002) e Eldenburg e Wolcott (2007) foram mencionados apenas uma vez, em um dos planos da UFCG. Santos (2009) obteve apenas uma menção em um dos planos da UFPB. E os autores Johnson e Kaplan (2001), Perez Jr. (2003) e Robles Junior (2003) foram mencionados apenas em um dos planos da UEPB.

Confrontando os resultados obtidos no presente estudo e a pesquisa de Sombra et al. (2015) destaca-se grande semelhançaem ambos os trabalhos. Tanto em relação 
Análise da Disciplina de Contabilidade de Custos nos Cursos de Graduação em Ciências Contábeis nas Universidades Públicas do Estado da Paraíba no ano de 2019

Wilton Alexandre de Melo, Marcia Cristina Leite Menino, Mauriceia Carvalho Nascimento, Ilcleidene

Pereira de Freitas, Bruno Rodrigues Cabral

ao autor mais citado, Martins (2010), quanto às demais referências, como: Horngren, Datar e Foster (2004), Maher (2001), Hansen e Mowen (2000).

\section{CONSIDERAÇÕES FINAIS}

A fim de identificar o perfil das disciplinas da área de contabilidade de custos nos cursos de graduação em Ciências Contábeis nas universidades públicas da Paraíba, objetivou-se verificar os planos de ensino das disciplinas da área de custos nos cursos de graduação em ciências contábeis, ofertados pelas IES públicas da Paraíba. Buscando compreender de forma comparativa a nomenclatura das disciplinas que abordam contabilidade de custos, estrutura dos planos de ensino, principais conteúdos abordados, metodologias de ensino e procedimentos de avaliação e referências utilizadas.

Sendo assim, constatou-se que em relação às nomenclaturas utilizadas, há certa uniformidade, pois três dos quatro cursos analisados apresentam a mesma nomenclatura. No que tange a estrutura dos planos de ensino, sete dos dez itens identificados foram mencionados em todos os planos, demonstrando similaridades entre eles. Apenas os itens "habilidades e competências", "horário de atendimento" e "cronograma" apareceram com certa discrepância. Em relação aos conteúdos abordados, nota-se uma vasta pluralidade de conteúdo, por serem de grande complexidade são trabalhados de forma detalhada.

No que concerne as metodologias utilizadas por parte dos docentes, apresentouse como método mais usual a "aula expositiva" e a "resolução de exercícios em grupo e individual" e menos utilizada "pesquisa bibliográfica", "seminário" e "trabalhos escritos". Quanto aos procedimentos de avaliação de aprendizagem a "prova objetiva/subjetiva" é a forma mais utilizada, por sua vez "relatório prático" e "resolução de exercícios" foram apontadas como menos utilizada. Por fim, verificaram-se as referências bibliográficas, o livro "Contabilidade de Custos" de Martins (2010) foi o mais citado, chegando a alcançar $100 \%$ da amostra, contudo fora observado também uma grande pluralidade de 
Análise da Disciplina de Contabilidade de Custos nos Cursos de Graduação em Ciências Contábeis nas Universidades Públicas do Estado da Paraíba no ano de 2019

Wilton Alexandre de Melo, Marcia Cristina Leite Menino, Mauriceia Carvalho Nascimento, Ilcleidene

Pereira de Freitas, Bruno Rodrigues Cabral

bibliografias, sendo mencionada trinta no total. Após o alcance dos resultados, foi confrontado os resultados obtidos no presente estudo em relação aos alcançados por Sombra et al. (2015). Os quais indicaram similaridades no que se referem às estruturas dos planos, metodologias, técnicas de avaliação e referências utilizadas. No entanto, apresentaram certa divergência em relação aos conteúdos e as nomenclaturas utilizadas.

Para a realização de estudos futuros, recomenda-se a aplicação deste estudo nas IES privadas que ofertem o curso de Ciências Contábeis na Paraíba, a fim de comparar os resultados identificados nesse estudo, bem como a análise do perfil de outras disciplinas da graduação em contabilidade.

\section{REFERÊNCIAS}

Associação Brasileira de Normas Técnicas. (2018). ABNT NBR 6023: Informação e documentação: Referências: Elaboração: Rio de Janeiro: ABNT.

Brasil. Ministério da Educação. (2004). Resolução CNE/CES n. 10/2004, de 16 de dezembro de 2004.2 Recuperado de: Portal.mec.gov.br/cne/arquivos/pdf/rces10_04.pdf>. Acesso em: 18 out.2019.

. UFCG. Resolução CNE/CES n 07/2004-A, de 17 de julho de 2016. <Recuperado de: http://www.ufcg.edu.br/ costa/resolucoes/res 16042016.pdf> Acesso em: 15/out./2019.

Cardoso, R. L., Pereira, C. A. \& Guerreiro, R. (2007). Perfil das pesquisas em contabilidade de custos apresentadas no EnANPAD no período de 1998 a 2003. Rev. Adm. Contemp, v.11, n.3, p.177-198.

Duarte, A. M., Cruz, V. L., Santos, R. R., Neto, G. J. S., Lagioia, U. C. T., \& Santos, A. A. (2016). Reprovação em Disciplinas do Curso de Ciências Contábeis de uma Instituição de Ensino Superior Paraibana: uma análise na visão dos discentes com ênfase na contabilidade de custos. In: Congresso Brasileiro de Custos, ABC, 2016. Anais [...].

Fernandes, J. L. N., Soares, D. R., Fernandes, B. A. F., Soares, J. R., \& Silva, L. B. (2015). Os desafios do ensino da disciplina contabilidade de custos face ao 
Análise da Disciplina de Contabilidade de Custos nos Cursos de Graduação em Ciências Contábeis nas Universidades Públicas do Estado da Paraíba no ano de 2019 Wilton Alexandre de Melo, Marcia Cristina Leite Menino, Mauriceia Carvalho Nascimento, Ilcleidene Pereira de Freitas, Bruno Rodrigues Cabral

panorama contemporâneo da economia brasileira. Revista e Contabilidade da UFBA, Salvador, v. 9, n. 1, p.05-21.

Ferreira, A. C. S. (2009). O Ensino da contabilidade mudanças nos cursos de Ciências Contábeis - Questão de currículo ou mentalidade? Contabilidade Vista \& Revista, v. 4, n. 1, p. 03-08, 18 abr.

Ferreira, A. F., Splitter, K., Borgert, A., Borba, J. A., \& Bellen, H. M. V. (2011). Contabilidade de custos nas universidades norte-americanas: o perfil da disciplina nos cursos de graduação. Congresso Brasileiro de Custos, Rio de Janeiro, Brasil, 18.

Ferreira, R. J. (2009). Contabilidade básica. (7a ed.). Rio de Janeiro: Ed. Ferreira.

Gerhardt, T. E., \& Silveira, D. T. (org.). (2009). Métodos de Pesquisa. Porto Alegre: Editora UFRGS.

Gil, A. C. (2012). Métodos e técnicas de pesquisa social. (6a ed.). São Paulo: Atlas.

Guimaraes, M. L., Cittadin, A., Giassi, D., Guimarães Filho, L. P., \& Bristot, V. M. (2016). Reflexos do uso de metodologias ativas no ensino da contabilidade de custos. ABCustos, São Leopoldo: Associação Brasileira de Custos, v. 11, n. 3, p. 60-84, set. /dez.

Hansen, D. R., \& Mowen, M. M. (2013). Cost Management: Accounting and Control. 4. reimpr. São Paulo: Cengage Learning.

Itoz, C., \& Mineiro, M. (2005). Ensino-aprendizagem da contabilidade de custos: componentes, desafios e inovação prática. Enfoque Reflexão Contábil, v. 24, n. 2, p. 53-65.

Leone, G. S. G. (2008). Custos planejamento, implantação e controle. (3a ed.). São Paulo: Editora Atlas.

Libaneoa, J. C. (2006). Didática. 26. reimpr. São Paulo: Cortez.

Luckesi, C. C. (2006). Avaliação da aprendizagem escolar. (18a ed.). São Paulo: Cortez.

Maher, M. (2001). Contabilidade de custos: criando valor para a administração. São Paulo: Atlas.

Marion, J. C. (2009). Contabilidade básica. (10a ed.). - 2. reimpr. - São Paulo: Atlas. 
Análise da Disciplina de Contabilidade de Custos nos Cursos de Graduação em Ciências Contábeis nas Universidades Públicas do Estado da Paraíba no ano de 2019 Wilton Alexandre de Melo, Marcia Cristina Leite Menino, Mauriceia Carvalho Nascimento, Ilcleidene Pereira de Freitas, Bruno Rodrigues Cabral

Martins, E. (2010). Contabilidade de custos. (10a ed.). - 6. reimpr. São Paulo: Atlas.

Nossa, V. (1999). Formação do corpo docente dos cursos de graduação em contabilidade no Brasil: uma análise crítica. Caderno de Estudos da Fipecafi, São Paulo, v. 11, n. 21, p. 74-92, maio/ago.

Ott, E. \& Pires, C. B. (2010). Estrutura curricular do Curso de Ciências Contábeis no Brasil versus estruturas curriculares propostas por organismos internacionais: uma análise comparativa. Revista Universo Contábil, v. 6, n. 1, p. 28-45.

Padoan, F. A. C., Almeida, L. B., Kühl, M. R., \& Leite, R. M. (2007). Métodos e técnicas utilizados no ensino da disciplina de Contabilidade de Custos em cursos de Ciências Contábeis: um estudo exploratório em instituições públicas de ensino superior no estado do Paraná. In: Congresso Brasileiro de Custos, João Pessoa, PB, Brasil, 14.

Padoveze, C. L. (2010). Contabilidade gerencial: um enfoque em sistema de informação contábil. (7a ed.). 3. reimpr. São Paulo: Atlas.

UEPB. (2019). Projeto Pedagógico do Curso: Ciências Contábeis CCSA. Campina Grande: $\quad$ EDUEPB, 2016.2 Recuperado de: $<$ http://proreitorias.uepb.edu.br/prograd/download/0100-2016-PPC-Campus-ICCSA-Ciencias-Contabeis-ANEXO.pdf> Acesso em: 15/out./2019.

(2019). Projeto Pedagógico do Curso: Ciências Contábeis CCHE. Monteiro: $\quad 2016.2$ Recuperado de: $<$ http://proreitorias.uepb.edu.br/prograd/download/0116-2016-PPC-Campus-VICCHE-Ciencias-Contabeis-ANEXO.pdf> Acesso em: 15/out./2019.

UFPB. (2019). Matriz curricular. Recuperado de: http://www.ccae.ufpb.br/ccae/contents/documentos/cursos/Contabeis/matrizcurricular/1-matrizcurricularcontabeisufpbatual-doc.pdf> Acesso em: 15/out./ 2019.

Richardson, R. J. (2008). Pesquisa social: métodos e técnicas. (3a ed.). 8. Reimp. São Paulo: Atlas.

Silva, A. C. R. (2008). Ensino da contabilidade: alguns aspectos sugestivos e críticos da graduação após resultados do Exame Nacional de Desempenho de Estudantes (ENADE) 2006. Revista Universo Contábil, v. 4, n. 3, p. 82-94, out. 2008.

Recuperado

de: 
Análise da Disciplina de Contabilidade de Custos nos Cursos de Graduação em Ciências Contábeis nas Universidades Públicas do Estado da Paraíba no ano de 2019

Wilton Alexandre de Melo, Marcia Cristina Leite Menino, Mauriceia Carvalho Nascimento, Ilcleidene Pereira de Freitas, Bruno Rodrigues Cabral

<https://gorila.furb.br/ojs/index.php/universocontabil/article/view/982/736>.

Acesso em: 27/out./2019.

Silva, M. A., \& Souza, K. G. (2012). Contabilidade de Custos e exames nacionais: análise da aderência dos conteúdos curriculares ao ENADE e Exame de Suficiência do CFC. In: Congresso Brasileiro de Custos, ABC, 2012. Anais [...].

Silva, R. N. S. (1995). O impacto do novo ambiente fabrilno ensino tradicional de custos: uma abordagem sobre o ensino da disciplina contabilidade de custos. In: Congresso Brasileiro de Gestão Estratégica de Custos, Campinas, SP, Brasil, 2.

Sombra, A. M. M., Pessoa, M. N. M., Cabral, A. C. A., Santos, S. M. dos., \& Silva, J. D. (2015). Perfil da disciplina de contabilidade de custos nas universidades brasileiras: uma análise nos cursos de graduação em ciências contábeis. In: Congresso Brasileiro de CustosFoz do Iguaçu, PR. Brasil, 22.

Tosi, M. R. (2006). Didática geral: um olhar para o futuro. (3a ed.). Campinas: Alínea.

Data de Submissão: 05/10/2020

Data de Aceite: 15/12/2020 